doi: $10.2306 /$ scienceasia1513-1874.2012.38.250

\title{
The neuroprotective effects of voluntary exercise in a restraint stress model
}

\author{
Nopporn Jongkamonwiwat, Warin Krityakiarana* \\ Division of Physical Therapy, Faculty of Health Science, Srinakharinwirot University, Thailand \\ ${ }^{*}$ Corresponding author, e-mail: warink@swu.ac.th
}

Received 2 Apr 2012

Accepted 8 Sep 2012

\begin{abstract}
Cell damage and cell generation can be altered in a stressed and exercised brain. However, it is not known whether voluntary exercise can prevent cell damage or cell death in stress situations, especially in the striatal region. To address this question, male Sprague-Dawley rats (3 months old) were separated into three groups (sedentary, restraint stress, and voluntary exercise + restraint stress groups). The stress circumstances were restraint stress, light stress, and tilt cage. To assess cell damage, staining for the heat shock protein (HSP90) was undertaken and the numbers of cells showing positive HSP90 expression were counted. Neurogenesis was investigated by staining for nestin markers. The restraint stress effects were assessed by determining the number of HSP90 expressed cells produced in the dorsal striatum. A significant difference was found when the number of HSP90 positive cells in the restraint stress and the voluntary exercise + restraint stress groups were compared to those in the sedentary control group. In both experimental conditions there was neurogenesis in the striatal area. However, the group that received voluntary exercise presented a significantly higher number of nestin-expressing cells over the restraint stress group. Voluntary exercise might have an adaptive effect on neurogenesis in terms of replenishing the cellular stressed neurons but it has no effect on ameliorating the level of stress marker. The evaluation of the effects of voluntary exercise on neurogenesis in the striatal region in the stressed model might contribute to a better understanding of beneficial interventions in movement disorders related to patients with depression.
\end{abstract}

KEYWORDS: heat shock protein, neurogenesis, physical therapy, brain, depression

\section{INTRODUCTION}

Adult neurogenesis depends on numerous factors, including age, disease, neurotrophic factors, neurotransmitters, inflammation, and levels of physical and mental activity ${ }^{1-4}$. Neurogenesis also appears to respond to a variety of environmental changes within the brain, such as stress, hormonal changes, and exercise ${ }^{1}$. Stress activates the hypothalamopituitary-adrenal (HPA) axis, triggering the release of corticortropin-releasing hormone from the hypothalamus; a cascade of signals triggers the release of glucocorticoids from the adrenal cortex, which can act on neurons displaying the appropriate receptor in the brain. Different types of stress decrease proliferation and neurogenesis in rodents, especially in the hippocampal regions ${ }^{2,5}$. Stress plays a crucial role in the progression of different pathologies. Imaging studies have shown that the volumes of the hippocampus $^{6}$, striatum ${ }^{7,8}$, and frontal cortex ${ }^{9}$ are decreased in patients with depression. A number of studies have identified numerous environmental factors that regulate adult neurogenesis and affect behaviour, possibly via neurogenesis-dependent mechanisms ${ }^{4,10}$. Chronic stress induces depressive behaviour and reduces the proliferation of new neurons ${ }^{3}$. One of the factors attributed to stress-induced impairment of brain function is decreased neurogenesis, particularly in the hippocampal dentate gyrus. Stress has been shown to affect the dopaminergic system in the striatal region which is responsible for the control of movement and might influence the pathology of movement disorders ${ }^{11}$. The striatum is composed of two distinct parts, the dorsal striatum and the ventral striatum. The dorsal striatum has been considered to encompass a motor function and deterioration of this area results in movements disorders including Parkinson's disease and Huntington's disease ${ }^{12}$. Psychophysiological stress situations, such as heat stress, intense physical exercise, and the use of various psychoactive and addictive drugs, induce the expression of heat shock proteins (HSPs)' messenger RNA and/or protein ${ }^{13}$. The expression of HSPs has been revealed to be a sensitive marker of metabolic activation or oxidative stress which results from increased metabolism levels and the hyperthermia conditions induced. Thus HSP is an important marker for detecting stress responses.

Restraint stress is an important method for phys- 
ical operation and as a model for psychiatric stress. This method involves immobilization or restriction of the range of locomotion in animals, which is inexpensive and harmless to the animal subject. It is straightforward, painless, and without lasting debilitation ${ }^{14}$. Moreover, restraint stress has been proved and used as a common stress inducing model ${ }^{15-17}$. Physical stress situations in rodents may be a useful model of early adversity and depression and the mechanism may involve alterations in neurotrophins ${ }^{18,19}$. Exercise has an implementional effect on neurotrophic expression in clinical and rodent studies similar to antidepressant administration ${ }^{20}$. Numerous studies have pointed towards an interaction between antidepressants, exercise and neurotrophin expression including the up-regulation of brain-derived neurotrophic factor (BDNF) mRNA in the striatum after voluntary exercise ${ }^{21}$, and increasing BDNF levels in the hippocampus after acute treadmill running ${ }^{22}$. BDNF has been shown to activate the cascade of signalling pathways and transcription factors which influence the expression of various proteins involved with the regulation of neural plasticity, stress resistance and cell survival.

The beneficial effects of exercise on brain functions have been observed in numerous studies. The effects of exercise were verified on cell proliferation and neurogenesis in mice in which acute stress had been induced. The animals responded to exercise with increased cell proliferation and neurogenesis in the dentate gyrus ${ }^{23}$. Physical activity increases the number of new cells and improves performance in learning ${ }^{24}$. Exercise also appears to protect neurons from destruction in the substantia nigra of maternally separated rat pups ${ }^{25}$.

However, the protective effects of voluntary exercise on cell formation in the striatum have not yet been investigated. The majority of studies examining neurogenesis in the context of stress and exercise have examined the effects on cell proliferation, especially in the hippocampal region. In contrast, very few stress studies and no running studies have examined the effects of these factors in the striatal region. In addition, it is interesting to consider the possible protective effects of voluntary exercise in the restraint stress model in relation to neurogenesis. In the present study, we examined whether voluntary exercise could protect the striatal cells from deterioration and encourage neurogenesis in the restraint stress model. Immunohistochemistry was used to verify heat shock protein (HSP90) expression, comparing the restraint stress-induced group, the voluntary exercise + restraint stress-induced group and the sedentary control group.

\section{MATERIALS AND METHODS}

\section{Animal preparation}

This project was approved by the Committee for Experimental Animal Research of the Faculty of Medicine, Srinakharinwirot University, Thailand (No. 1/2554). Male Sprague-Dawley rats (3 months old) were used in this experiment. The rats were housed under standard laboratory conditions $(12 \mathrm{~h} /$ $12 \mathrm{~h} \mathrm{light/dark} \mathrm{cycle;} \mathrm{lights} \mathrm{on} \mathrm{at} \mathrm{6:00} \mathrm{am;} \mathrm{food} \mathrm{and}$ water supplied ad libitum).

\section{Stress induction protocols}

Sprague-Dawley rats were divided into three groups: restraint stress-induced, voluntary exercise + restraint stress-induced group, and sedentary (eight rats/group). The stress induction protocols were performed using the following procedure: The animals were put into separate Plexiglas cylindrical cages, the diameter and length of which were adjusted to accommodate the size of each animal. The restraint stress was performed $4 \mathrm{~h}$ daily during the dark phase of the cycles. During restraint stress, the cage was tilted and bright light was shone to increase the stress to the animal.

\section{Voluntary exercise}

The exercised rats were housed in individual cages with a running wheel (diameter $=31.8 \mathrm{~cm}$, width $=$ $10 \mathrm{~cm}$ ) and left free to run. The number of running cycles were continuously recorded by an automatic cycle counter which recorded the level of voluntary exercise. The animals that ran more than 500 rounds per night consecutively for 14 nights were classified in the voluntary exercise group. The selected animals were then instantly put under restraint stress for 7 days. Animals were sacrificed immediately after the last session of stress induction.

\section{Tissue preparation and immunohistochemistry}

The brains of the rats in all three groups-restraint stress-induced, voluntary exercise + restraint stressinduced group, and sedentary control-were excised after the last session of the stress induction. The animals were deeply anaesthetized using sodium pentobarbital (Nembutal) and were then transcardially perfused with $4 \%$ paraformaldehyde. The brains were rapidly removed, post-fixed overnight in $4 \%$ paraformaldehyde, and then cryoprotected in solutions containing $30 \%$ sucrose. The brains were then embedded in optimal cutting temperature compound and frozen in liquid nitrogen. Coronal sections $(20 \mu \mathrm{m})$ were taken using a cryostat. Immunohistochemistry was performed in line with previous litera- 
ture $^{26}$. In brief, the sliced tissues were permeabilized with $0.3 \%$ Triton $\mathrm{X}$ in PBS for $10 \mathrm{~min}$, treated with $10 \%$ donkey serum for $15 \mathrm{~min}$ in PBS containing $0.3 \%$ Triton X-100 to block nonspecific binding, and then incubated with appropriate primary antibodies against Heat Shock Protein-90 (HSP90, Santa Cruz, CA), double-labelled with anti-nestin (Amersham Pharmacia Biotech, Piscataway, NJ) in PBS containing 3\% albumin at $4{ }^{\circ} \mathrm{C}$ overnight. After being washed twice with PBS containing Tween $20(0.1 \%)$ for $30 \mathrm{~min}$, the sections were incubated with FITC- and rhodamineconjugated secondary antibodies in PBS containing $3 \%$ albumin for $1 \mathrm{~h}$ and then washed twice. All tissue slides were mounted using Vectashield mounting medium. The sliced tissues were examined using a laser-scanning confocal microscope (Zeiss). The numbers of immunopositive stained cells were determined and averaged for the entire field of the image from four consecutive sections within the striatal area.

\section{Cell counting and statistical analysis}

The density of HSP90 was detected and measured through immunostaining and confocal microscope study in the striatal area of the animals. The animals were sacrificed immediately after seven days of stress protocol to determine the effects of stress on the striatal neurons. The numbers of nestin-expressing and HSP90-expressing cells in the striatal area of the brain were counted using four consecutive sections per animal. In order to gain a more detailed picture of the distribution of the positive cells for counting, each section of the striatum was divided into quadrants of roughly equal size. Areas were measured using the NIH Image program on images captured using a digital camera system. Within each section, the boundaries of the dorsal striatum were established. In brief, the sections examined were located caudal to the nucleus accumbens and rostral to the globus pallidus according to the atlas of Paxinos and Watson as previous work has shown that the pattern of cells in this region of the dorsal striatum ${ }^{27}$. The results of the cell counts were reported as the mean \pm SD numbers of positive cells averaged in each group. Statistical analysis was performed by one-way ANOVA followed by Tukey's test. The level of significance was established at $p<0.05$.

\section{RESULTS}

The tissue samples from the striatal area were analysed to determine the level of expression of HSP90 and nestin. The sedentary control group clearly displayed low expression of both HSP90 and nestin positive cells. Conversely, the voluntary exercise +
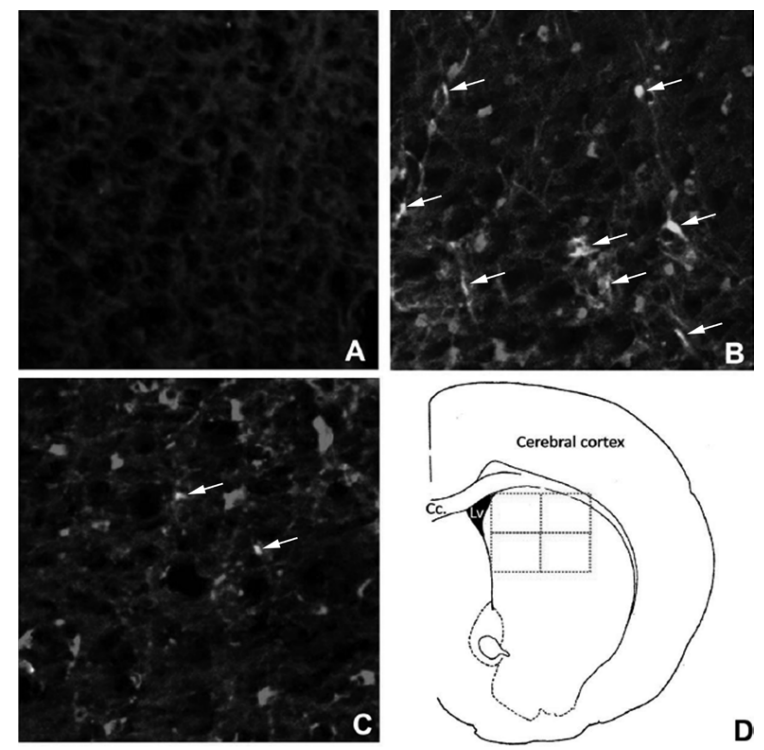

Fig. 1 Expression of HSP-90 and Nestin positive (arrows) in the dorsal striatum of the brain in (A) sedentary, (B) voluntary exercise + restraint stress-induced, and (C) restraint stress-induced animals. (D) Representative $20 \mu \mathrm{m}$ striatal section illustrating the location for cell counting in the dorsal striatal area. Cc.: Corpus callosum; Lv.: Lateral ventricle.

restraint stress-induced and restraint stress-induced groups tended to express HSP90 in numerous cells of the dorsal striatum. The nestin positive immunoreactivity was marked predominantly in the voluntary exercise group over the stress-induced group alone (Fig. 1).

The expression values of each marker in the different experimental groups were quantified from four consecutive sections from the striatal region of each animal (Fig. 2). HSP90 was highly expressed in the stress-induced group. A significant difference was found when comparing the number of HSP90 positive cells in the restraint stress-induced group and the voluntary exercise + restraint stress-induced group to the sedentary control group $(p<0.05)$. Nevertheless, there was no significant difference between the restraint stress-induced and voluntary exercise + restraint stress-induced groups.

A very limited number of cells expressed nestin in the sedentary control group (Fig. 2). We found the number of nestin positive cells was clearly expressed in the voluntary exercise + restraint stress-induced group. The results showed a significant difference between the three groups when the number of nestin positive cells in the restraint stress-induced group was compared to those in the voluntary exercise + restraint 


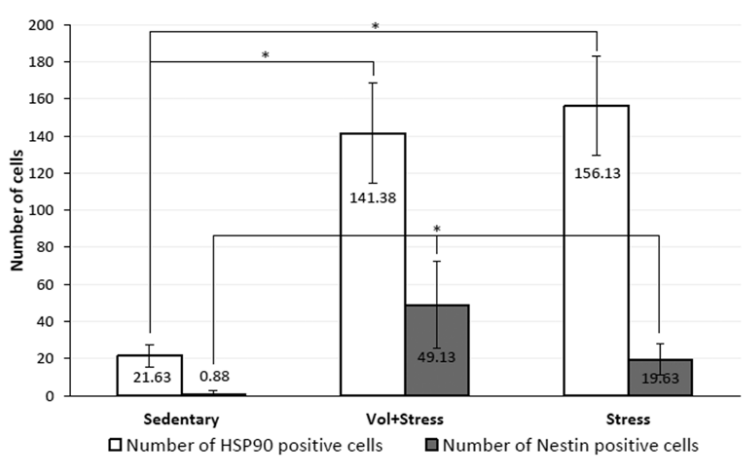

Fig. 2 Expression of HSP-90 in both voluntary exercise + restraint stress-induced (Vol+Stress) and restraint stressinduced induced group. There was no significant different of HSP-90 between the stress induced and voluntary exercise + stress induced groups. Voluntary exercise promotes neuroprogenitor cells (represented by nestin expression) and showed statistical different over the stress induced and sedentary control group. $\left({ }^{*} p<0.05\right)$.

stress-induced group and in the sedentary control group $(p<0.05)$.

\section{DISCUSSION}

In this study we have demonstrated the expression of HSP90 immunoreactivity in the dorsal striatum in a restraint stress model. Our results provide evidence that restraint stress induced the expression of HSP90 in the dorsal striatum in line with an increase in physiological responses to cellular stress ${ }^{28}$. Previous research has shown that the association between stress and striatal apoptosis may be related to the circulating levels of corticosteroids ${ }^{27}$. The number of apoptotic striatal cells seen in the dorsomedial region of the striatum suggests that this number may be correlated with how stressed the animals were. Regarding the specific association of HSPs with the glucocorticoid receptor (GR), HSP90 assists GR to achieve hormone binding conformation ${ }^{29}$. Moreover, the binding of glucocorticoids triggers GR translocation to the nucleus where it regulates the transcription of a wide variety of genes. The processes of GR nuclear translocation ${ }^{30}$ and GR transcriptional activity ${ }^{31}$ are also dependent on HSP90 chaperone machineries. Conversely, it has been reported that HSP expression plays a protective role and provides tolerance against cellular stress. It is involved in the modulation of proteolytic machinery, preventing protein misfolding and aggregation, thereby accelerating cellular repair processes ${ }^{32}$. In this experiment, voluntary exercise did not alter the level of HSP90 expression when com- pared to the restraint stress-induced group. However, the level of HSP90 expression appears to be a reliable marker for studying cellular stress in the striatal area in response to restraint stress. This result is supported by a previous study which showed that HSP90 protein levels and genes gradually increased in the central nervous system (CNS) with stress and age ${ }^{33}$. Another previous study reported that the basal HSP90 level is significantly increased in the blood cells of elderly human subjects ${ }^{34}$. They suggested that higher levels of HSP90 might be due to the higher load of damaged proteins.

We have also shown that the conditions in both the restraint stress-induced and voluntary exercise + restraint stress-induced groups drive neurogenesis in the striatal area. However, the group that received voluntary exercise before stress induction presented a significantly higher number of nestin-expressing cells over the restraint stress-induced group. This result supports previous studies which found that voluntary wheel running enhanced neurogenesis in mice ${ }^{35,36}$. Brain-derived neurotrophic factor, IGF-1 (insulin like growth factor-1), and neurotrophin are the particular neurotrophic factors which are related to cell survival and cell proliferation. Several studies have found that voluntary exercise increases the level of these factors in CNS, which might also have the effect of modulating the number of neuroprogenitor cells in CNS. In particular, IGF-1 is known to be involved in enhancing proliferation, preventing apoptosis and inducing the differentiation of neuroprogenitor cells ${ }^{37,38}$. Running also resulted in a very significant reduction of corticosterone (CORT) levels in $\mathrm{CNS}^{23}$. This might be one mechanism to explain the effect of voluntary exercise in decreasing the CORT level. Despite various evidence which has shown that the activation of the HPA axis had a suppressive effect on adult neurogenesis, glucocorticoids have been involved in the stress-induced impairment of adult neurogenesis. There are some types of behaviour that activate the HPA axis but are associated with enhanced rates of adult neurogenesis. For instance, physical exercise augments cell proliferation, neuronal differentiation and the survival of new neurons in the dentate gyrus of the adult mouse ${ }^{39,40}$ and rat ${ }^{41,42}$. Thus it is possible that by employing voluntary exercise before stress induction the model in this study did not entirely eliminate the level of stress signals, but extensively activated neurogenesis as an adaptive response to cellular stress. The effects of voluntary exercise may not be able to moderate the stress marker, HSP90, as we observed no significant difference between HSP90 in voluntary exercise before stress induction 
and restraint stress alone. However, voluntary exercise can have attainable effects on neurogenesis and might play a crucial role in replenishing damaged cells. Elevated levels of neurogenesis were also found in the restraint stress group. A number of studies have recently demonstrated that selective neuronal death or degeneration in regions such as the cerebral cortex and striatum of adult mammals can induce modest levels of neurogenesis ${ }^{43,44}$. Nevertheless, the forming of the new neurons does not seem as robust as that in the voluntary exercise animals.

Despite this finding, we cannot rule out that voluntary exercise has an explicit effect in preventing the expression of stress markers in the striatal region. An increase in neurogenesis due to the effect of voluntary exercise might lead to the restitution of neuroprogenitor cells as a response to the stress affected striatal cells cessation. Further study is needed to verify the stress hormone level, cell proliferation markers and/ or apoptosis markers to gain an understanding of the exact mechanism by which voluntary exercise impacts restraint stress. The evaluation of the effects of voluntary exercise on neurogenesis in the striatal region in relation to the restraint stress model might contribute to a better understanding of what interventions are beneficial in treating movement disorders related to patients with depression.

\section{REFERENCES}

1. Balu DT, Lucki I (2009) Adult hippocampal neurogenesis: regulation, functional implications, and contribution to disease pathology. Neurosci Biobehav Rev 33, 232-52.

2. Castilla-Ortega E, Hoyo-Becerra C, Pedraza C, Chun J, Rodríguez De Fonseca F, Estivill-Torrús G, Santín LJ (2011) Aggravation of chronic stress effects on hippocampal neurogenesis and spatial memory in $\mathrm{LPA}_{1}$ receptor knockout mice. PLOS ONE 6, e25522.

3. Drew MR, Hen R (2007) Adult hippocampal neurogenesis as target for the treatment of depression. CNS Neurol Disord Drug Targets 6, 205-18.

4. Lieberwirth C, Wang Z (2012) The social environment and neurogenesis in the adult Mammalian brain. Front Hum Neurosci 6, 118.

5. Tanti A, Rainer Q, Minier F, Surget A, Belzung C (2012) Differential environmental regulation of neurogenesis along the septo-temporal axis of the hippocampus. Neuropharmacology 63, 374-84.

6. Sawyer K, Corsentino E, Sachs-Ericsson N, Steffens DC (2012) Depression, hippocampal volume changes, and cognitive decline in a clinical sample of older depressed outpatients and non-depressed controls. Aging Ment Health 16, 753-62.

7. Pizzagalli DA, Holmes AJ, Dillon DG, Goetz EL, Birk JL, Bogdan R, Dougherty DD, Iosifescu DV, et al (2009) Reduced caudate and nucleus accumbens response to rewards in unmedicated individuals with major depressive disorder. Am J Psychiatr 166, 702-10.

8. Butters MA, Aizenstein HJ, Hayashi KM, Meltzer CC, Seaman J, Reynolds CF III, Toga AW, Thompson PM, Becker JT (2009) Three-dimensional surface mapping of the caudate nucleus in late-life depression. Am J Geriatr Psychiatr 17, 4-12.

9. Chang CC, Yu SC, McQuoid DR, Messer DF, Taylor WD, Singh K, Boyd BD, Krishnan KR, et al (2011) Reduction of dorsolateral prefrontal cortex gray matter in late-life depression. Psychiatr Res 193, 1-6.

10. Kramer AF, Bherer L, Colcombe SJ, Dong W, Greenough WT (2004) Environmental influences on cognitive and brain plasticity during aging. $J$ Gerontol Biol Med Sci 59, M940-57.

11. Metz GA (2007) Stress as a modulator of motor system function and pathology. Rev Neurosci 18, 209-22.

12. Kung VW, Hassam R, Morton AJ, Jones S (2007) Dopamine-dependent long term potentiation in the dorsal striatum is reduced in the R6/2 mouse model of Huntington's disease. Neuroscience 146, 1571-80.

13. McEwen BS (2004) Protection and damage from acute and chronic stress: allostasis and allostatic overload and relevance to the pathophysiology of psychiatric disorders. Ann New York Acad Sci 1032, 1-7.

14. Buynitsky T, Mostofsky DI (2009) Restraint stress in biobehavioral research: Recent developments. Neurosci Biobehav Rev 33, 1089-98.

15. Bowman RE, Ferguson D, Luine VN (2002) Effects of chronic restraint stress and estradiol on open field activity, spatial memory, and monoaminergic neurotransmitters in ovariectomized rats. Neuroscience 113, 401-10.

16. Gao Y, Bezchlibnyk YB, Sun X, Wang JF, McEwen BS, Young LT (2006) Effects of restraint stress on the expression of proteins involved in synaptic vesicle exocytosis in the hippocampus. Neuroscience 141, 1139-48.

17. O'Mahony CM, Sweeney FF, Daly E, Dinan TG, Cryan JF (2010) Restraint stress-induced brain activation patterns in two strains of mice differing in their anxiety behaviour. Behav Brain Res 213, 148-54.

18. Nyhuis TJ, Masini CV, Sasse SK, Day HE, Campeau S (2010) Physical activity, but not environmental complexity, facilitates HPA axis response habituation to repeated audiogenic stress despite neurotrophin mRNA regulation in both conditions. Brain Res 1362, 68-77.

19. Luo KR, Hong CJ, Liou YJ, Hou SJ, Huang YH, Tsai SJ (2010) Differential regulation of neurotrophin S100B and BDNF in two rat models of depression. Progr Neuro Psychopharmacol Biol Psychiatr 34, 1433-9.

20. Van Praag HM (2005) Can stress cause depression? World J Biol Psychiatr 6 Suppl 2, 5-22.

21. Marais L, Stein DJ, Daniels WM (2009) Exercise increases BDNF levels in the striatum and decreases 
depressive-like behavior in chronically stressed rats. Metab Brain Dis 24, 587-97.

22. Soya H, Nakamura T, Deocaris CC, Kimpara A, Iimura M, Fujikawa T, Chang H, McEwen BS, Nishijima $\mathrm{T}$ (2007) BDNF induction with mild exercise in the rat hippocampus. Biochem Biophys Res Comm 358, 961-7.

23. Kannangara TS, Webber A, Gil-Mohapel J, Christie BR (2009) Stress differentially regulates the effects of voluntary exercise on cell proliferation in the dentate gyrus of mice. Hippocampus 19, 889-97.

24. Jin J, Jing H, Choi G, Oh MS, Ryu JH, Jeong JW, Huh Y, Park C (2008) Voluntary exercise increases the new cell formation in the hippocampus of ovariectomized mice. Neurosci Lett 439, 260-3.

25. Mabandla MV, Russell VA (2010) Voluntary exercise reduces the neurotoxic effects of 6-hydroxydopamine in maternally separated rats. Behav Brain Res 211, $16-22$.

26. Krityakiarana W, Espinosa-Jeffrey A, Ghiani CA, Zhao PM, Topaldjikian N, Gomez-Pinilla F, Yamaguchi M, Kotchabhakdi N, de Vellis J (2010) Voluntary exercise increases oligodendrogenesis in spinal cord. Int $\mathrm{J} \mathrm{Neu}$ rosci 120, 280-90.

27. Mitchell IJ, Cooper AJ, Griffiths MR, Barber DJ (1998) Phencyclidine and corticosteroids induce apoptosis of a subpopulation of striatal neurons: a neural substrate for psychosis? Neuroscience 84, 489-501.

28. Kultz D (2005) Molecular and evolutionary basis of the cellular stress response. Annu Rev Physiol 67, 225-57.

29. Grad I, Picard D (2007) The glucocorticoid responses are shaped by molecular chaperones. Mol Cell Endocrinol 275, 2-12.

30. Pratt WB, Galigniana MD, Harrell JM, DeFranco DB (2004) Role of hsp90 and the hsp90-binding immunophilins in signalling protein movement. Cell Signal 16, 857-72.

31. Stavreva DA, Muller WG, Hager GL, Smith CL, McNally JG (2004) Rapid glucocorticoid receptor exchange at a promoter is coupled to transcription and regulated by chaperones and proteasomes. Mol Cell Biol 24, 2682-97.

32. Richter-Landsberg C, Goldbaum O (2003) Stress proteins in neural cells: functional roles in health and disease. Cell Mol Life Sci 60, 337-49.

33. Ghi P, Di Brisco F, Dallorto D, Osella MC, Orsetti M (2009) Age-related modifications of egr1 expression and ubiquitin-proteasome components in pet dog hippocampus. Mech Ageing Dev 130, 320-7.

34. Njemini R, Lambert M, Demanet C, Kooijman R, Mets T (2007) Basal and infection-induced levels of heat shock proteins in human aging. Biogerontology $\mathbf{8}$, 353-64.

35. Kannangara TS, Lucero MJ, Gil-Mohapel J, Drapala RJ, Simpson JM, Christie BR, van Praag H (2010) Running reduces stress and enhances cell genesis in aged mice. Neurobiol Aging 32, 2279-86.
36. van Praag H, Shubert T, Zhao C, Gage FH (2005) Exercise enhances learning and hippocampal neurogenesis in aged mice. J Neurosci 25, 8680-5.

37. Anderson MF, Aberg MA, Nilsson M, Eriksson PS (2002) Insulin-like growth factor-I and neurogenesis in the adult mammalian brain. Dev Brain Res 134, 115-22.

38. Kumar S, Biancotti JC, Yamaguchi M, de Vellis J (2007) Combination of growth factors enhances remyelination in a cuprizone-induced demyelination mouse model. Neurochem Res 32, 783-97.

39. Snyder JS, Glover LR, Sanzone KM, Kamhi JF, Cameron HA (2009) The effects of exercise and stress on the survival and maturation of adult-generated granule cells. Hippocampus 19, 898-906.

40. Klaus F, Hauser T, Slomianka L, Lipp HP, Amrein I (2009) A reward increases running-wheel performance without changing cell proliferation, neuronal differentiation or cell death in the dentate gyrus of C57BL/6 mice. Behav Brain Res 204, 175-81.

41. Stranahan AM, Khalil D, Gould E (2006) Social isolation delays the positive effects of running on adult neurogenesis. Nat Neurosci 9, 526-33.

42. Yi SS, Hwang IK, Yoo KY, Park OK, Yu J, Yan B, Kim IY, Kim YN, et al (2009) Effects of treadmill exercise on cell proliferation and differentiation in the subgranular zone of the dentate gyrus in a rat model of type II diabetes. Neurochem Res 34, 1039-46.

43. Gonzalez-Castaneda RE, Galvez-Contreras AY, Luquin S, Gonzalez-Perez O (2011) Neurogenesis in Alzheimer's disease: a realistic alternative to neuronal degeneration? Curr Signal Transduct Ther 6, 314-9.

44. Luzzati F, De Marchis S, Parlato R, Gribaudo S, Schutz G, Fasolo A, Peretto P (2011) New striatal neurons in a mouse model of progressive striatal degeneration are generated in both the subventricular zone and the striatal parenchyma. PLOS ONE 6, e25088. 